\title{
Dynamics of lagoon ecosystems
}

\author{
F. Cioffi \& G. Cannata \\ Dipartimento di Idraulica, Trasporti e Strade, \\ Università degli Studi di Roma 'La Sapienza', Italy
}

\begin{abstract}
The dynamic behaviour of a lagoon ecosystem is investigated by using an eutrophication model. The phosphorous external load is assumed as control parameter. The response diagram, obtained by simulation, varying the value of control parameter, shows the existence of different ranges of stability of the ecosystem, characterized by the dominance of a specific group of primary produces and by a different ecosystem vulnerability to Summer water anoxia. A catastrophic bifurcation occurs for a critical value of the control parameter, which manifests as an abrupt change of the dominant specie from eelgrass to macroalgae. The serious consequences of such a selection in terms of eutrophication processes, anoxic crisis vulnerability and management policies for ecosystems subject to alternate states are emphasised.
\end{abstract}

Keywords: lagoon, mathematical models, eutrophication.

\section{Introduction}

Lagoon ecosystems exhibit a complex dynamic which is due to non linear interactions of biological, chemical and hydrodynamic processes that influence the cycles of carbon (vegetal growth, organic detritus production and mineralization), nutrients, sulphur, and of all those species playing any role in ecological phenomena $[1,5,7,8]$. Such a dynamic is influenced by various external forcing variables - tidal flow rate, wind speed, temperature, light intensity, nutrient external load - that in most of the cases are periodical or multi-periodical. Anthropogenic or natural changes in one or more of these external variables, can trigger shifts between ecosystem states which can be evidenced by species composition shift, higher vulnerability of the lagoon to Summer water anoxia, more frequent fish kills. These regime shifts can be 
smooth, abrupt or discontinuous; furthermore they may not be immediately reversible $[2,6]$.

The understanding of the mechanisms driving the regime shifts and of their reversibility or irreversibility character, appears to be fundamental to individuate strategies to management lagoon ecosystems.

In this paper the ecosystem dynamic in lagoons, as a consequence of nutrient enrichment, was investigated by an eutrophication model [3, 4]. The rate of phosphorous external load was assumed as control parameter. A diagram representing the ecosystem dynamic response to the changes of the control parameter was constructed by simulations. Such a response diagram suggests the existence of regime shifts which border different ecosystem stability ranges, characterized by the dominance of a specific group of primary producers and by a different ecosystem vulnerability at Summer water anoxia. A catastrophic bifurcation or abrupt regime shift- evidenced by Poincarè sections obtained mapping, at a prefixed time period, the values of the concentration of the species - occurs for a critical value of the control parameter and manifests itself as an abrupt change of the dominant specie from eelgrass to macroalgae.

\section{Hypothesis and model equations}

The model simulates, in water column and in sediments, the concentration temporal evolution of the species: dissolved oxygen, vegetal organic carbon, particulate and dissolved organic carbon, orthophosphate, hydrogen sulphide, adsorbed phosphorous [3,4]. Such a model is applied to an hypothetical and schematic lagoon, having superficial area A, tidal flow rate $\mathrm{q}$, and a constant depth $\mathrm{h}$. Horizontal homogeneity is assumed and the two main hydrodynamic effects on eutrophication processes - turbulent diffusion and flushing of the species from the lagoon toward the sea- are represented respectively by vertical turbulent diffusion terms, (whose turbulent diffusion coefficient is related to the instantaneous value of tidal flow rate and wind speed [3]) - and sink/source terms related to the tidal flow rate and to the volume of the lagoon.

The mass balance equations of the model are the following:

$$
\begin{aligned}
& \frac{\partial C_{a l}}{\partial t}=\frac{\partial}{\partial z}\left(v_{t} \frac{\partial C_{a l}}{\partial z}\right)+\left(\mu_{c r a l} \cdot f_{a}\left(P_{o}\right) \cdot f(I) \cdot f_{a l}(T)-r_{a l} f_{a l}(T)-\frac{K_{d a l}}{f_{a l}(T)}-\frac{K_{p_{a l}}}{f_{a l}(T)}\right) \cdot C_{a l}+ \\
& +\alpha_{a l} \cdot(q /(A \cdot h)) \cdot \sin \left(\omega_{m} t\right) \cdot \widetilde{C}_{a l} \\
& \frac{\partial C_{p h}}{\partial t}=\frac{\partial}{\partial z}\left(v_{t} \frac{\partial C_{p h}}{\partial z}\right)+\left(\mu_{c p h} \cdot f_{p h}\left(P_{o}\right) \cdot f(I) \cdot f_{p h}(T)-r_{p h} f_{p h}(T)-\frac{K_{d p h}}{f_{p h}(T)}-\frac{K_{p_{p h}}}{f_{p h}(T)}\right) \cdot C_{p h}+ \\
& +(q /(A \cdot h)) \cdot \sin \left(\omega_{m} t\right) \cdot \widetilde{C}_{p h} \\
& \quad \frac{d \widetilde{C}_{m}}{d t}=\int_{0}^{h}\left(\mu_{c r m} \cdot f_{s}\left(P_{o}, P_{a d s}\right) \cdot f(I) \cdot f_{m}(T)-r_{m} \cdot f_{m}(T)-\frac{K_{d m}}{f_{m}(T)}-\frac{K_{p_{m}}}{f_{m}(T)}\right) \cdot C_{m} d z \\
& \quad \widetilde{C}_{m}=\int_{0}^{h} C_{m}(z) d z \quad ; \quad C_{m}(z)<C_{\max } \\
& \frac{\partial C_{d}}{\partial t}=\frac{\partial}{\partial z}\left(v_{t} \frac{\partial C_{d}}{\partial z}\right)+\frac{K_{d a l}}{f_{a l}(T)} \cdot C_{a l}+\frac{K_{d m}}{f_{m}(T)} \cdot C_{m}+\frac{K_{d p h}}{f_{p h}(T)} \cdot C_{p h}-\mu_{d} \cdot f_{\mu}(T) \cdot f\left(C_{d}\right) \cdot f\left(O_{2}\right)+\quad(4) \\
& K_{p} C_{p} \alpha_{p o r}-K_{s} C_{d}+(q /(A \cdot h)) \cdot \sin \left(\omega_{m} t\right) \cdot \widetilde{C}_{d}+q_{d m m}
\end{aligned}
$$




$$
\begin{aligned}
& \frac{\partial C_{p}}{\partial t}-v_{s} \frac{\partial C_{p}}{\partial z}=\frac{\partial}{\partial z}\left(v_{t} \frac{\partial C_{p}}{\partial z}\right)-K_{p} C_{p}+\frac{K_{p_{a l}}}{f_{a l}(T)} \cdot C_{a l}+\frac{K_{p_{m}}}{f_{m}(T)} \cdot C_{m}+\frac{K_{p_{p h}}}{f_{p h}(T)} \cdot C_{p h}+ \\
& +(q /(A \cdot h)) \cdot \sin \left(\omega_{m} t\right) \cdot \widetilde{C}_{p}+q_{p i m m} \\
& \frac{\partial P_{O}}{\partial t}=\frac{\partial}{\partial z}\left(v_{t} \frac{\partial P_{O}}{\partial z}\right)+K_{p_{c}}\left(\mu_{d} \cdot f_{\mu}(T) \cdot f\left(C_{d}\right) \cdot f\left(O_{2}\right)+K_{s} C_{d}\right)+ \\
& -K_{p c}\left(\mu_{c r a l} f_{a}\left(P_{O}\right) f(I) f_{a l}(T)-r_{a l} f_{a l}(T)\right) \cdot C_{a l}+ \\
& -K_{p c}\left(\mu_{c p h} \cdot f_{p h}\left(P_{o}\right) \cdot f(I) \cdot f_{p h}(T)-r_{p h} f_{p h}(T)\right) \cdot C_{p h}+ \\
& -\frac{1-p_{o r}}{p_{o r}} \cdot K_{a}\left(P_{a e}-P_{a}\right)+\alpha_{p}\left(\frac{1-p_{o r}}{p_{o r}}\right)+ \\
& -\left(\left(\mu_{c r m} \cdot f_{s}\left(P_{O}, P_{a d s}\right) \cdot f(I) \cdot f_{m}(T)\right)-f_{m}(T) \cdot r_{m}\right) \cdot \frac{\widetilde{C}_{m} K_{p m c}}{h_{s}} \cdot f^{\prime}(z)+ \\
& +(q /(A \cdot h)) \cdot \sin \left(\omega_{m} t\right) \cdot \widetilde{P}_{O}+q_{q p_{o} i m m} \\
& \frac{d P_{a}}{d t}=K_{a}\left(P_{a e}-P_{a}\right)-\alpha_{p}-\left(\mu_{c r m} \cdot f_{s}\left(P_{0}, P_{a}\right) \cdot f_{m}(I) \cdot f_{m}(T)-f_{m}(T) \cdot r_{m}\right) \cdot \frac{\widetilde{C}_{m} K_{p m c}}{h_{s}} \cdot f^{\prime \prime}(z) \\
& \frac{\partial H}{\partial t}=\frac{\partial}{\partial z}\left(v_{t} \frac{\partial H}{\partial z}\right)-K_{H} O H+\alpha_{s} \cdot K_{s} C_{d}+(q /(A \cdot h)) \cdot \sin \left(\omega_{m} t\right) \cdot \tilde{H} \\
& \frac{\partial O}{\partial t}=\frac{\partial}{\partial z}\left(v_{T} \frac{\partial O}{\partial z}\right)+\alpha_{\mu} \cdot\left(\mu_{c p h} \cdot f_{p h}\left(P_{o}\right) \cdot f(I) \cdot f_{p h}(T)-r_{p h} f_{p h}(T)-\frac{K_{d p h}}{f_{p h}(T)}-\frac{K_{p p h}}{f_{p h}(T)}\right) \cdot C_{p h}+ \\
& +\alpha_{\mu} \cdot\left(\mu_{c r a l} \cdot f_{a}\left(P_{O}\right) \cdot f(I) \cdot f_{a l}(T)-r_{a l} \cdot f_{a l}(T)-\frac{K_{d a l}}{f_{a l}(T)}-\frac{K_{p_{a l}}}{f_{a l}(T)}\right) \cdot C_{a l}+ \\
& +\alpha_{\mu} \cdot\left(\mu_{c r m} \cdot f_{s}\left(P_{O}, P_{a}\right) \cdot f(I) \cdot f_{m}(T)-r_{m} \cdot f_{m}(T)-\frac{K_{d_{m}}}{f_{m}(T)}-\frac{K_{p_{m}}}{f_{m}(T)}\right) \cdot C_{m}+ \\
& -\beta_{1} \cdot \mu_{d} f_{\mu}(T) \cdot f\left(C_{d}\right) \cdot f\left(O_{2}\right)-\beta_{2} K_{H} O H+\alpha_{o}(q /(A \cdot h)) \cdot \sin (\omega t) \cdot \widetilde{O}
\end{aligned}
$$

The meaning of the symbols of Eqs (1)-(9) is reported in the Appendix. Eqs (1)-(3) refer to the three main groups of primary producers [8] - eelgrass $C_{m}$ (as Zostera), macro-algae $C_{a l}$ (as Ulva) and micro-algae or phytoplankton $C_{p h}$ (as Chlorella) - whose vegetal growth, by photosynthesis, is controlled by environmental factor - light, temperature, lagoon hydrodynamics - and by the physiological characteristics of the particular vegetal specie; the three species differ respect to nutrient uptake, growth and organic detritus production rates. The eelgrass (as Zostera) is a rooted vegetal specie, while the other two are floating ones; eelgrass assimilates phosphorous mainly by root-rhizomes from the interstitial water of the sediment [1] and it growths starting from the bottom of the water column, then the vegetation extends to the upper layers of the water column once a maximum vegetal concentration $\left(\mathrm{C}_{\max }\right.$ in Eq. (3)) is reached in the lower layers. Floating species uptake phosphorous in the water column and they growth mainly near the free surface of the water column where there are more favourable light conditions. In Eqs (1)-(3) the nutrient uptake is represented by Michaelis-Menten kinetics, $V=V_{\max }\left(P /\left(P+K_{s}\right)\right.$, where $V$ is the uptake velocity, $V_{\max }$ the maximum uptake velocity (which directly related to the algae growth rate), $P$ the concentration of nutrient and $K_{s}$ the half-saturation constant. Low 
values of $K_{s}$ are thought to express a competitive advantage for algal species at low nutrient concentrations, whilst those algae with higher values of $V_{\max }$ are considered to be favoured at higher concentrations. Experimental studies in aquatic ecosystems [9] have shown that both the values of $V_{\max }$ and $K_{s}$ depend on the algae size (or by surface/volume ratio, $\mathrm{S} / \mathrm{V}$ ): the maximum $\mathrm{PO}_{4}$ uptake small algae capacity per unit volume is higher than large algae one, whereas $K_{s}$ decreases with increasing algae size. The rate of production of organic detritus by rooted plants is lower than in floating species and it has appreciable values only at the end of the eelgrass life cycle; on the contrary the floating species, having a quickly turn over, during the entire life cycle, show a greater and more uniform detritus production rates. These rates increase with increasing of algae $\mathrm{S} / \mathrm{V}$ ratio. On the basis of these observations the vegetal growth rates, the organic detritus production rates and the half-saturation constant were related to the $\mathrm{S} / \mathrm{V}$ ratio [5]. Eqs (4)-(5) represent the mass balances, in water and sediments, of both dissolved $C_{d}$ and particulate organic detritus $C_{p}$; in Eqs (4)-(5) different processes are represented: vegetal organic detritus production, transformation of $C_{p}$ in $C_{d}$, settling, aerobic and anaerobic mineralization. Eqs (6)-(7) represent the dissolved phosphorous mass balance, in water and in sediments, and the adsorbed phosphorous mass balance in sediments. The following processes are represented: aerobic and anaerobic adsorbing-desorbing of dissolved phosphorous in sediments, phosphorous uptakes by vegetal species, source of phosphorous by aerobic and anaerobic mineralization. Eqs (8) represent the mass balance of sulphide produced by anaerobic mineralization processes (sulphide reduction) and consumed by re-oxidation. Eqs (9) represent the dissolved oxygen mass balance as a consequence of photosynthesis, algal respiration, aerobic mineralization, sulphide re-oxidation.

Periodical forcing terms appears into the model equations. They represent the influences of external variables - as light, temperature, tidal flow rate, breeze speed - having some typical periodicity or multi-periodicity: light and temperature have both seasonal and daily variation, tidal flow rate has a semidaily variation, breeze speed has a daily variation.

Semi-discretization of Eqs (1)-(9) in the space variable $z$, on discrete points along the vertical, yields a $\mathrm{nN}$ ODE system, $\mathrm{n}$ being the number of points of the grid and $\mathrm{N}$ the species number. A non equidistant grid was used in order to obtain a better approximation of the derivates close to the interface air- water and water-sediment. The ODE system, for assigned boundary conditions (see [3, 4]), was solved using a forth order Runge-Kutta method.

\section{Procedure and results}

In order to analyse the response of the ecosystems to the variations of nutrient load discharged in the lagoon the described procedure was followed:

a) In order to define the parameter space, a set of biological, chemical and physical parameters (on the basis of literature) and external forcing variables was selected; the parameter values are reported in the Appendix; 
b) the phosphorous load $\mathrm{q}_{\text {poimm }}$ was assumed as control parameter whose value has been changed within a prefixed range;

c) for each selected value of the control parameter a simulation by model was carried out as long as periodic solutions of the equation system were reached; the existence of periodical solutions was verified observing the evolution of the system in the phase space projected to significant couples of variables of the system;

d) a Poincarè section was constructed mapping the values of the concentration of the species, describing the state of the system, at a prefixed time for each simulated year; this time was chosen at the end of July, at 6.00 a.m, corresponding to a very critical Summer condition, i.e. a breeze with a four-day Summer stop period. It should be noted that a periodic solution of the dynamic systems, which in the phase space is described by a limit cycle, in a Poincarè section appears as a fixed point;

e) a response (or bifurcation) diagram, depicting the values at the fixed points of the more significant variables vs. the control parameter values was constructed.

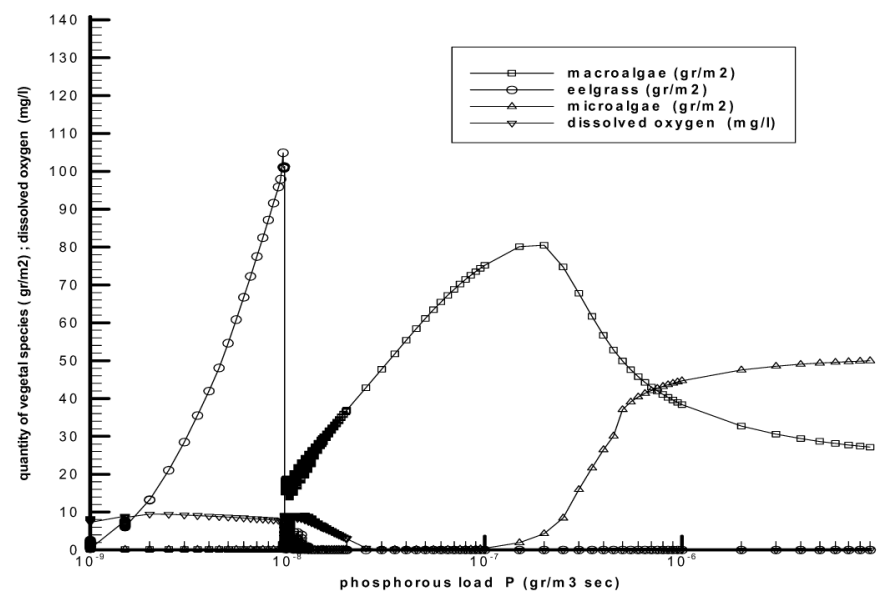

Figure 1: Response diagram.

In fig. 1 the response diagram is shown; in the diagram the values, corresponding to the fixed points, of three vegetal species concentrations, integrated along the water column depth, and of the dissolved oxygen concentration at the bottom of the water column, are reported vs. phosphorous load $\left(\mathrm{gr} / \mathrm{m}^{3} \mathrm{~s}\right)$. The figure shows that, varying the phosphorous load, different lagoon trophic conditions occur. These conditions are characterised by the dominance of a specific vegetal specie. It is possible to identify three regions defined by the values of the control parameter $\mathrm{q}_{\text {poimm }}$ :

a) $\mathrm{q}_{\text {poimm }}<10^{-8} \mathrm{gr} / \mathrm{m}^{3} \mathrm{~s}$, region I: eelgrass is the only specie present in lagoon; values of dissolved oxygen concentration are generally greater than $4 \mathrm{mg} / \mathrm{l}$; no Summer water anoxia occurs; 
b) $10^{-8}<\mathrm{q}_{\mathrm{poimm}}<10^{-7} \mathrm{gr} / \mathrm{m}^{3} \mathrm{~s}$, region II: macroalgae is the only dominant specie; for values of $\mathrm{q}_{\mathrm{pimm}}>210^{-8}$ the values of minimum Summer dissolved oxygen concentration are practically null; this means that lagoon is subject each year to water anoxia phenomena;

c) $10^{-7}<\mathrm{q}_{\text {poimm }} \mathrm{gr} / \mathrm{m}^{3} \mathrm{~s}$, region III: macroalgae and microalgae coexists. For $\mathrm{q}_{\mathrm{poimm}}>810^{-7}$ microalgae is the dominant species. Also in this region the minimum Summer dissolved oxygen concentration values are null denoting water anoxia phenomena.

The evolution in time of the ecosystems for an assigned value of the control parameter can be analysed in the phase space projected to two or more significant species. The adsorbed phosphorous concentration vs. the eelgrass concentration is shown in the phase plane in figure 2 . Figure 2 is obtained by the calculated temporal series of the specie concentrations. An example of these temporal series is shown in figure 3. Figures 2 and 3 refers to the simulation with $\mathrm{q}_{\text {poimm }}=510^{-9}$. Figure 2 represents a typical behaviour of the ecosystem in the region I: after the transitory, a periodical solution is obtained, clearly shown by the existence of the limit cycle shown in figure 2 .

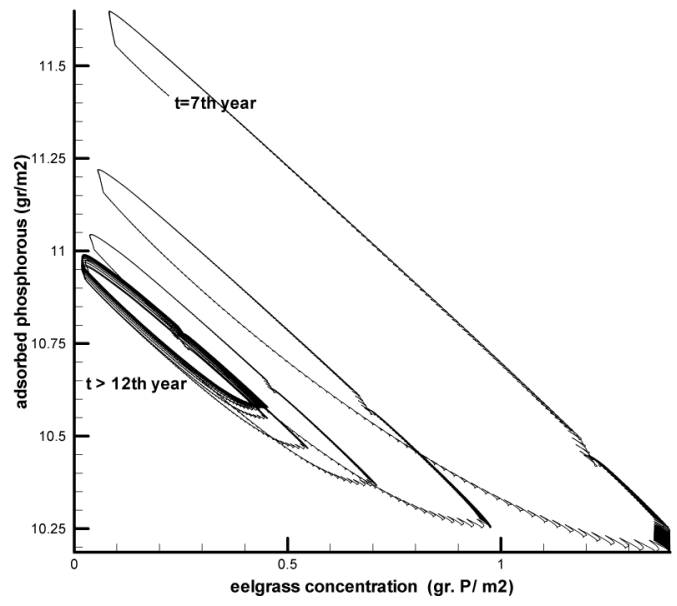

Figure 2: $\quad$ Phase plane.

In figure 2 the higher values of the concentration of eelgrass correspond to lower values of adsorbed phosphorous concentration in sediments and vice versa: in fact eelgrass uptakes phosphorous from sediments, thus the quantity of adsorbed phosphorous reduces; at the end of the eelgrass life cycle the dissolved phosphorous produced by detritus mineralization is ready transformed in adsorbed phosphorus; the good oxygenation conditions of the environmental favourites the last process. In the first region the orthophosphate concentration in water column is so low to prevent the floating algae growth. The phase plane in figure 4 shows the orthophosphate concentration in water column vs. macroalgae concentration; figure 4 refers to a simulation in which a phosphorous load value 
within the region II was assumed $\left(\mathrm{q}_{\text {poimm }}=510^{-8}\right)$; from the figure 4 is possible to observe that, after the transitory, the trajectories collapse in a limit cycle. From the figure it is possible to observe that, in coherence with the macroalgae growth cycle, at higher macroalgae concentration values correspond lower orthophosphate concentration values and vice versa. In region II macroalgae is the dominant vegetal specie. This can be explained observing that, in region II, the orthophosphate concentrations in the water column, resulting from the balance between the phosphorous discharged into the lagoon and the one flushing from the lagoon to the sea, are high enough to allow the macroalgae growth, but not so high to support the microalgae growth. Furthermore eelgrass growth is inhibited by the shadowing due to the presence of macroalgae [3]. In figure 5 the two limit cycles are shown related to, respectively, macroalgae and microalgae concentration vs. orthophosphate concentration in water column. Figure 5 refers to a phosphorous load value $\left(\mathrm{q}_{\text {poimm }}=510^{-7}\right)$ within the region III. The two limit cycles present a very complex feature and no clear relation exists between the concentration of available phosphorous for algae growth and algae concentration, like in the cases of figure 2 and 4. This is due to the fact that, during the entire Summer period, frequent water anoxia occur also in presence of breeze winds; such a quasi- permanent water anoxia condition determinates the release from sediment to water column of the adsorbed phosphorous in dissolved phosphorous. The phosphorous, released from sediments, affects the phosphorous balance in the water column masking the effect of algae uptakes. Figure 1 shows that an abrupt change in vegetal specie composition, from eelgrass to macroalgae, occur within the small range of values $910^{-9}<\mathrm{q}_{\text {poimm }}<$ $10^{-8} \mathrm{gr} / \mathrm{m}^{3} \mathrm{~s}$. In order to investigate this qualitative and ' catastrophic' change in the ecosystem behaviour numerous simulations were carried out, in the previously indicated range, varying the control parameter of a quantity $\Delta \mathrm{q}_{\text {poimm }}=2$ $10^{-11} \mathrm{gr} / \mathrm{m}^{3} \mathrm{~s}$. Thus Poincarè sections were constructed mapping, at prefixed times with period $\mathrm{T}=1$ year, the values of the concentration of the species (see the description of point d)). In figures 6 and 7 the most significant results of this analysis are shown. Figure 6 represents the Poincarè section related to eelgrass vs. macroalgae concentrations. The letter $A$ in figure 6 indicates the point in which the trajectories describing the evolution of the state of the ecosystem in the first year of simulation intersect the Poincarè section; the letter $\mathrm{B}$ and $\mathrm{C}$ in figure 6 represent the fixed points, corresponding to limit cycles in the phase space, obtained by simulations in which two very close values of $\mathrm{q}_{\text {poimm }}$ were assumed $\left(\mathrm{q}_{\text {poimm }}=9.6610^{-9}\right.$ and $\left.\mathrm{q}_{\text {poimm }}=9,6810^{-9}\right)$. The two curves in figure 6 describe very close trajectories which form a spiral cycle, but once in the center of the spiral the two curves move in opposite directions towards the respective fixed points. This bifurcation behaviour is a direct consequence of the nonlinearity of the equation system representing the ecosystem. It should be deducted by figure 6 that eelgrass and macroalgae are mutually exclusive; in fact the fixed point $\mathrm{B}$ represents a state of the ecosystem in which only eelgrass is present, whereas, the fixed point $\mathrm{C}$ represent a state of the ecosystem in which macroalgae has completely replaced the eelgrass. In order to complete the analysis, in figure 7 the Poincarè section, constructed with the values of 
orthophosphate concentration vs. adsorbed phosphorous concentration, is shown; the figure 7 refers to the same simulations of figure 6 . The two fixed points $\mathrm{B}$ and $\mathrm{C}$ in figure 7 refer to the same state of the ecosystems of the fixed points $\mathrm{B}$ and $\mathrm{C}$ in figure 6 . Point $\mathrm{B}$ in figure 7 represents the state in which eelgrass is present, the dissolved phosphorous concentration is low, and the adsorbed phosphorous has been up-taken by eelgrass; while point $\mathrm{C}$ in figure 7 represents a state of the system in which the concentration of dissolved phosphorous is high enough to support the macroalgae growth; further the adsorbed phosphorous concentration is in chemical equilibrium with the dissolved one.

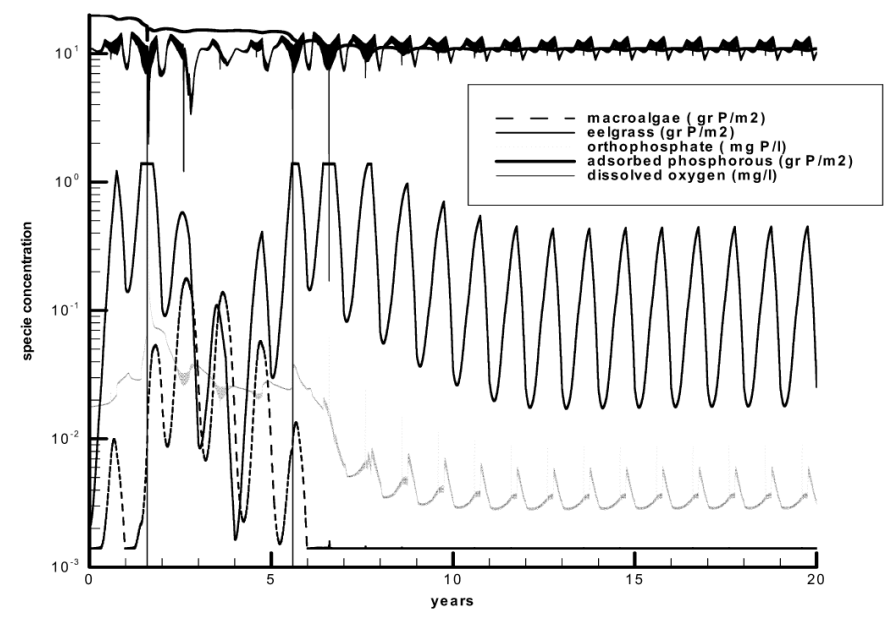

Figure 3: Species concentration vs. time.

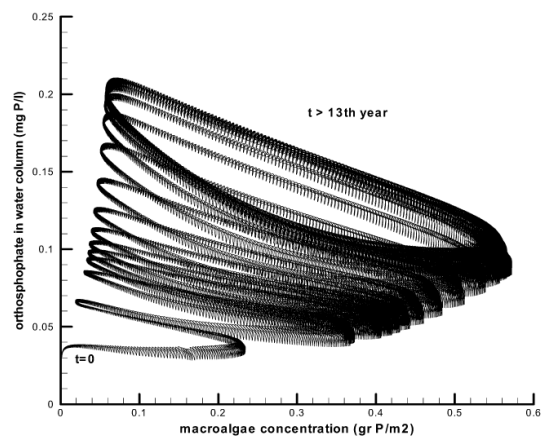

Figure 4: $\quad$ Phase plane.

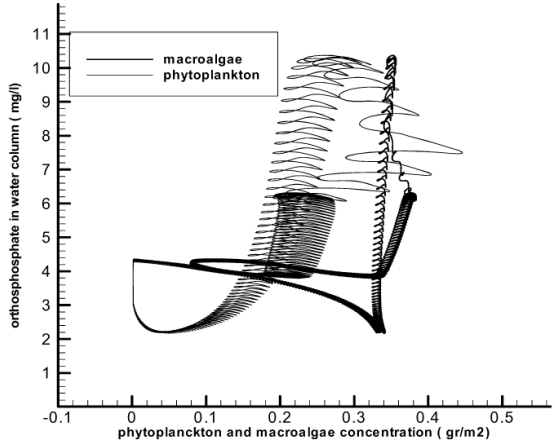

Figure 5: $\quad$ Phase plane. 


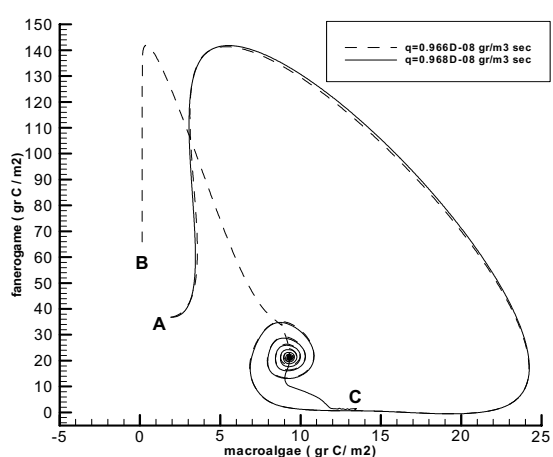

Figure 6: Poincarè section.

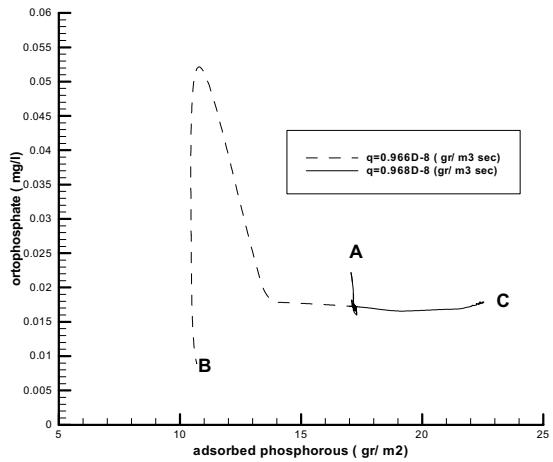

Figure 7: Poincarè section.

\section{Conclusion}

The analysis of the dynamic behaviour of a lagoon ecosystem conducted by the eutrophication model has evidenced: a) the existence of different ranges of stability of the ecosystem depending on the value of the external phosphorous load and characterized by the dominance of a specific group of primary producers; b) in the ranges of values of the external phosphorous load where floating algae are dominant the ecosystem has a greater vulnerability to Summer water anoxia; c) a catastrophic bifurcation occurs for a critical value of the control parameter which manifests with an abrupt substitution of eelgrass with macroalgae. Even if the results are encouraging the analysis conducted by simulations allows to individuate only the stable branches of response diagram; it does not allow the individuation of unstable branches; further it does not allow the geometrical characterization of bifurcation points. This characterization can be performed using continuation techniques. An attempt to apply these techniques to lagoon ecosystems is in progress.

\section{Appendix}

External forcing factor: A lagoon surface $\left(\mathrm{km}^{2}\right)$ 3.0; q tidal flow rate $\left(\mathrm{m}^{3} / \mathrm{s}\right) 4$; breeze speed $(\mathrm{m} / \mathrm{s}) 3.5$

$\mathrm{C}_{\max }$ maximum eelgrass concentration $(\mathrm{gr} \mathrm{C} / \mathrm{l})=100$

$\mathrm{D}_{\mathrm{mo}}, \mathrm{D}_{\mathrm{mn}} \quad \mathrm{O}_{2}, \mathrm{H}_{2} \mathrm{~S}$ diffusion coefficients $\left(\mathrm{m}^{2} / \mathrm{s}\right) 10^{-10}$

$f_{a l}\left(P_{o}\right)=P_{o} /\left(K_{p o a l}+P_{o}\right), f_{p h}\left(P_{o}\right)=P_{o} /\left(K_{p o p h}+P_{o}\right)$

$f_{s}\left(P_{o}, P_{a}\right)=\left(P_{o}+P_{a}\right) /\left(K_{p o s}+P_{o}+P_{a}\right)$ nutrient limiting factors

$f(O)=O /\left(K_{o}+O\right)$ oxygen limiting factor

$f\left(C_{d}\right)=C_{d} /\left(K_{d}+C_{d}\right)$ dissolved organic carbon limiting factor 
$f(I)=\left(I / I_{m}\right) \cdot \sin \left(\pi \cdot \omega_{y} \cdot\left(t-t_{s}\right)\right) \sin \left(\pi \cdot \omega_{d} \cdot\left(t-t_{s}\right)\right) \cdot e^{-\gamma \cdot(h-z)}$ light extinction

$f_{a l, p h}(T)=K_{t a l, p h}^{\left(T-T_{a l, p h}\right)}, f_{m}(T)=\left(T / T_{m}\right) \cdot e^{\left(1-\left(T / T_{m}\right)\right)}$,

$f_{\mu}(T)=K_{t \mu}{ }^{\left(T-T_{\mu}\right)}$ temperature limiting factors

$\mathrm{h}$ water column depth (m) 1.20

$\mathrm{h}_{\mathrm{s}}$ sediment layer depth (m.) 0.1

$\mathrm{K}_{\mathrm{a}}$ aerobic adsorbing-desorbing phosphorus rate in sediment $\left(\mathrm{s}^{-1}\right) 2.510^{-6}$

$\mathrm{K}_{\mathrm{d}}$ half saturation constant (aerobic mineralization) (mg/l) 10

$\mathrm{K}_{\mathrm{dal}}, \mathrm{K}_{\mathrm{dph}}, \mathrm{K}_{\mathrm{dm}}$ dissolved organic carbon production rate $\left(\mathrm{s}^{-1}\right) 10^{-7}, 10^{-6}, 510^{-8}$

$\mathrm{K}_{\mathrm{H}}$ reoxidation rate of Hydrogen sulphide $\left(\mathrm{s}^{-1}\right) 4.210^{-6}$

$\mathrm{K}_{\mathrm{o}}$ half saturation constant limiting aerobic mineralization (mg/l) 0.3

$\mathrm{K}_{\mathrm{pc}}, \mathrm{K}_{\mathrm{pmc}}\left(\mathrm{mg} / \mathrm{PO}_{4}^{-}\right) /\left(\mathrm{mg} / \mathrm{lC}_{\mathrm{al}, \mathrm{ph}, \mathrm{d}}\right) 0.01$

$\mathrm{K}_{\mathrm{p}}$ particulate organic in dissolved organic carbon rate $\left(\mathrm{s}^{-1}\right) 510^{-7}$

$\mathrm{K}_{\mathrm{pal}}, \mathrm{K}_{\mathrm{pph}}, \mathrm{K}_{\mathrm{pm}}$ particulate organic carbon production rate $\left(\mathrm{s}^{-1}\right) 10^{-7}, 10^{-6}, 510^{-8}$

$\mathrm{K}_{\mathrm{po}}$ adsorbed-dissolved phosphorus half saturation constant (mg/l) $510^{-3}$

$\mathrm{K}_{\text {poal }}, \mathrm{K}_{\text {poph }}, \mathrm{K}_{\text {pos }}$ half saturation constants ( $\left.\mathrm{mgPO}_{4} / \mathrm{l}\right)$ 0.02, 0.08, 0.01

$\mathrm{K}_{\mathrm{s}}$ organic carbon mineralization rate in anaerobic conditions $\left(\mathrm{s}^{-1}\right) 2.510^{-7}$

$\mathrm{K}_{\gamma 1} ; \mathrm{K}_{\gamma 2} ; \mathrm{K}_{\gamma 3} ; \mathrm{K}_{\gamma 4}$ extinction light coefficients $0.06,0.05,0.005,0.06$

$\mathrm{P}_{\mathrm{ae}}=\mathrm{P}_{\max }\left(\mathrm{P}_{\mathrm{o}} /\left(\mathrm{P}_{\mathrm{o}}+\mathrm{K}_{\mathrm{po}}\right)\right)$ equilibrium adsorbed phosphorous concentration

$\mathrm{P}_{\max }$ maximum adsorbed phosphorus concentration in sediments $(\mathrm{mg} / \mathrm{l}) 700$

$p_{\text {or }}$ porosity $=0,8$

$\mathrm{q}_{\text {pimm}}, \mathrm{q}_{\mathrm{dmm}}, \mathrm{q}_{\text {poimm }}$ external loads of particulate and dissolved carbon and phosphorous

$\mathrm{r}_{\mathrm{al}}, \mathrm{r}_{\mathrm{ph}}, \mathrm{r}_{\mathrm{m}}$ vegetal respiration rate $\left(\mathrm{s}^{-1}\right) 610^{-7}, 510^{-6}, 310^{-7}$

$\alpha_{\text {al }}$ hydrodynamic factor 0.05

$\alpha_{\mathrm{p}}$ anaerobic adsorbed phosphorus release rate in sediments $\left(\mathrm{s}^{-1}\right) 510^{-4}$

$\alpha_{\text {por }}$ equal to unity in the water column and equal to $\left(1-\mathrm{p}_{\mathrm{or}}\right) / \mathrm{p}_{\text {or }}$ in sediments

$\alpha_{\mathrm{s}}\left(\mathrm{mg} / \mathrm{l} \mathrm{H}_{2} \mathrm{~S}\right) /\left(\mathrm{mg} / 1 \mathrm{C}_{\mathrm{d}}\right) 0.88$

$\alpha_{\mu}(\mathrm{mg} / \mathrm{l} \mathrm{O} 2) /(\mathrm{mg} / \mathrm{l} \mathrm{C} \mathrm{al}, \mathrm{ph}, \mathrm{m}) 2.66$

$\beta_{1}, \beta_{2}$ stochiometric constant

$\gamma=\mathrm{K}_{\gamma 1} \mathrm{C}_{\mathrm{al}}+\mathrm{K}_{\gamma 2} \mathrm{C}_{\mathrm{ph}}+\mathrm{K}_{\gamma 3} \mathrm{C}_{\mathrm{m}}+\mathrm{K}_{\gamma 4} \mathrm{C}_{\mathrm{p}}$ light extinction factor

$\mu_{\text {cral }}, \mu_{\text {crph }}, \mu_{\text {crm }}$ vegetal growth rates

$\mu_{\mathrm{d}}$ aerobic mineralization rate $\left(\mathrm{s}^{-1}\right) 610^{-6}, 510^{-5}, 310^{-6}$

$v_{\mathrm{s}}$ settling velocity of particulate organic carbon $(\mathrm{m} / \mathrm{s})=110^{-6}$

$v_{t}$ turbulent diffusion coefficient and dispersion coefficient in sediments

$\omega_{\mathrm{y}}, \omega_{\mathrm{d}}, \omega_{\mathrm{m}}, \omega_{\mathrm{b}}$ yearly, daily, tidal and breeze speed periods (d) 365 ,(h)24,12,24

\section{References}

[1] Back H.K., A dynamic model describing the seasonal variations in growth and the distribution of eelgrass (Zostera marina L.), Ecological modelling, 65, 31-50, 1993

[2] Carpenter S.R., Ludwing D., Brock W.A., Management of eutrophication for lake subject to potentially irreversible change, Ecological Application, 9(3), pp.751-771, 1999 
[3] Cioffi F., Gallerano F., From rooted to floating vegetal species in lagoons as a consequence of the increases of external nutrient load: An analysis by model of the species selection mechanism, Applied Mathematical modelling, 30, 10-37, 2006

[4] Cioffi F., Gallerano F., Management strategies for the control of eutrophication processes in Fogliano lagoon (Italy) a long term analysis using a mathematical model, Applied Mathematical modelling, 25, 385-426, 2001

[5] Coffaro G., Bocci M., Bendoricchio G., Application of structural dynamic approach to estimate space variability of primary producers in shallow marine water, Ecological Modelling, 102, 97-114, 1997

[6] Collie J.S., Richardson K., Steele J.H., Regime shift: can ecological theory illuminate the mechanism?, Progress in Oceanography, 60, 281-302, 2004

[7] Raven J.A., Taylor R., Macroalgae growth in nutrient-enriched estuaries: A biogeochemical and evolutionary perspective, Water, air and soil pollution, 3: 7-26, 2003

[8] Sfriso A., Facca C., Ceoldo S., Marcomini A., Recording the occurence of trophic level changes in the lagoon of Venice over '90s, Environment international, 31, 993-1001, 2005

[9] Wen Y.H., Vezina A., Peters R.H., Allometric scaling of compartmental fluxes of phosphorous in freshwater algae, Limnol. Oceanogr., 42, 45-56, 1997 